\title{
Enhanced mechanical and corrosion properties of grain refined Mg-2.0Zn-0.5Zr-3.0Gd alloy
}

\author{
H. $\mathrm{Yao}^{1,2 *}, \mathrm{H} . \mathrm{Li}^{1}, \mathrm{Y} . \mathrm{Liu}^{1}, \mathrm{H} . \mathrm{Shi}^{1}$ \\ ${ }^{1}$ School of Materials Science and Engineering, Henan University of Science and Technology, \\ Luoyang Henan 471023, P. R. China \\ ${ }^{2}$ Collaborative Innovation Center of Nonferrous Metals of Henan Province, Luoyang Henan 471023, P. R. China
}

Received 26 April 2020, received in revised form 1 September 2020, accepted 9 September 2020

\begin{abstract}
The microstructure, mechanical and corrosion properties of $\mathrm{Mg}-2.0 \mathrm{Zn}-0.5 \mathrm{Zr}-3.0 \mathrm{Gd}$ alloys in four different states (as-cast, solid solution, as-cast extrusion, and solid solution extrusion) were studied. Results show that the microstructure of alloys in different states is mainly composed of equiaxed $\alpha$ - Mg matrix and $(\mathrm{Mg}, \mathrm{Zn})_{3} \mathrm{Gd}$ precipitates with different sizes. Among them, a small number of nano-sized $(\mathrm{Mg}, \mathrm{Zn})_{3} \mathrm{Gd}$ precipitates with a semi-coherent relationship with the matrix appeared in the solution-treated alloy. A large number of nano-elliptical $\mathrm{Mg}_{2} \mathrm{Zn}_{11}$ precipitates was found in the two extruded alloys. The temperature for dynamic crystallization of solid solution extruded alloy is higher than that of as-cast extruded alloy. The extruded solution-treated alloy exhibits the best mechanical properties and anticorrosive ability, which could be attributed to a more homogeneous microstructure, grain refinement, and the presence of nanometric secondary phase particles. Grain refined solution-treated alloy could have potential applications in metallic biomaterials.
\end{abstract}

K e y word s: magnesium alloys, microstructure, mechanical properties, corrosion, extrusion

\section{Introduction}

Magnesium (Mg) alloys are attractive as new generation biomedical temporary implant materials for orthopedic applications due to their good biocompatibility and biodegradation, similar mechanical properties to natural bone, and lower densities compared to other metallic biomaterials [1-4]. However, a rapid $\mathrm{Mg}$ corrosion rate in the human body, as well as a nonuniform corrosion mode, result in a premature loss of mechanical integrity that can lead to a collapse of the implant before the tissue is sufficiently healed [5]. Yet, $\mathrm{Mg}$ alloys with high mechanical properties, low corrosion rate, and uniform corrosion mode are crucial in biomedical applications [6].

Grain refinement improves mechanical properties and corrosion resistance. Realized via hot extrusion, the grain-refined $\mathrm{Mg}$ alloys were endowed with higher mechanical properties and corrosion resistance than the untreated ones [7-9]. For instance, high ultimate tensile strength (UTS) of $252.8 \pm 8.6 \mathrm{MPa}$, yield strength (YS) of $204.7 \pm 10.3 \mathrm{MPa}$, elongation (EL) of $14.6 \pm 0.4 \%$, and low corrosion rate were reached in as-cast $\mathrm{Mg}-2 \% \mathrm{Ca}$ alloy after hot extrusion [10], and the values turned to $320,268 \mathrm{MPa}$ and $16.6 \%$ respectively for the extruded $\mathrm{Mg}-5.3 \mathrm{Zn}-0.2 \mathrm{Ca}-0.5 \mathrm{Ce}$ alloy [11]. Even higher mechanical properties were reported for the extruded Mg-8.90Gd-5.11Y-3.10Zn-0.47Zr alloy, whose UTS and YS topped at 378 and $283 \mathrm{MPa}$, despite a relatively low EL of $11.5 \%$ [12]. The as-cast Mg-Gd-Zn-Zr-Mn alloy exhibits a YS of $315.2 \mathrm{MPa}$, EL of $21.3 \%$, and corrosion rate of less than $0.5 \mathrm{~mm} \mathrm{y}^{-1}$ after hot extrusion [13].

Despite this progress, a drawback is the undissolved secondary phase particles with a banding distribution along the extrusion direction (ED), impacting the mechanical properties and corrosion resistance $[14$, 15]. To eliminate such distribution of the secondary phase, the alloy is treated by solution heat treatment before hot extrusion. The advantage of solid-solution $\mathrm{Mg}$ alloys subjected to hot extrusions is that many secondary phases have been dissolved into the alloy matrix before being extruded. The secondary phases in alloys will re-precipitate as nanoscaled secondary

*Corresponding author: e-mail address: yaohuaitougao@126.com 
phase particles in the process of extrusion, distributed homogeneously in the matrix, with the result that the mechanical properties and corrosion resistance of alloys get greatly improved.

Considering the biological safety, a low Gd content $\mathrm{Mg}-2.0 \mathrm{Zn}-0.5 \mathrm{Zr}-3.0 \mathrm{Gd}$ alloy was designed in this paper. A hot extrusion process was first introduced to solution-treated $\mathrm{Mg}-2.0 \mathrm{Zn}-0.5 \mathrm{Zr}-3.0 \mathrm{Gd}$ alloy to enhance the mechanical properties and corrosion resistance. The influence of the secondary phase distribution, morphology, and size on the dynamic recrystallization (DRXed) temperature, structure, mechanical properties, and corrosion resistance of the alloy during extrusion were analyzed, with particular emphasis on the grain refinement mechanisms, morphology evolution mechanisms, and secondary phase strengthening mechanisms. It is hoped that the knowledge provided here will benefit bio implant materials design.

\section{Experimental procedure}

\subsection{Sample preparation}

Alloy ingot with a nominal composition Mg-2.0Zn-
-0.5Zr-3.0Gd (wt.\%) was fabricated by melting at a temperature of $710^{\circ} \mathrm{C}$ high-purity $\mathrm{Mg}$ (99.93 wt.\%) and $\mathrm{Zn}(99.93 \mathrm{wt} . \%)$ in an electronic induction furnace under the protection of $\mathrm{CO}_{2}+1 \% \mathrm{SF}_{6}$ mixed gas, with the addition of Mg-25Zr (wt.\%) and Mg-20Gd (wt.\%) master alloys. The molten alloys were held at $730^{\circ} \mathrm{C}$ for $\sim 5 \mathrm{~min}$, then poured into a mild steel mold preheated to $300^{\circ} \mathrm{C}$. The as-cast ingots were solutiontreated at $480^{\circ} \mathrm{C}$ for $8 \mathrm{~h}$, followed by quenching into the water at about $60^{\circ} \mathrm{C}$. The as-cast and solutiontreated ingots were machined into cylinders $50 \mathrm{~mm}$ in diameter and $35 \mathrm{~mm}$ high. The extrusion die was preheated to $300{ }^{\circ} \mathrm{C}$. The as-cast and solution-treated ingots were extruded into rods with a diameter of $18 \mathrm{~mm}$ at 350 and $360^{\circ} \mathrm{C}$, respectively, and air cooled. The extrusion speed was set at $5 \mathrm{~mm} \mathrm{~s}^{-1}$. Here, the former and latter were denoted as E350 and E360, respectively. All the extruded rods were annealed at $200^{\circ} \mathrm{C}$ for $4 \mathrm{~h}$.

\subsection{Characterization}

The as-extruded specimens for microstructure observation were cut to the ED. The characterization of samples was performed by optical microscopy (OLYM-
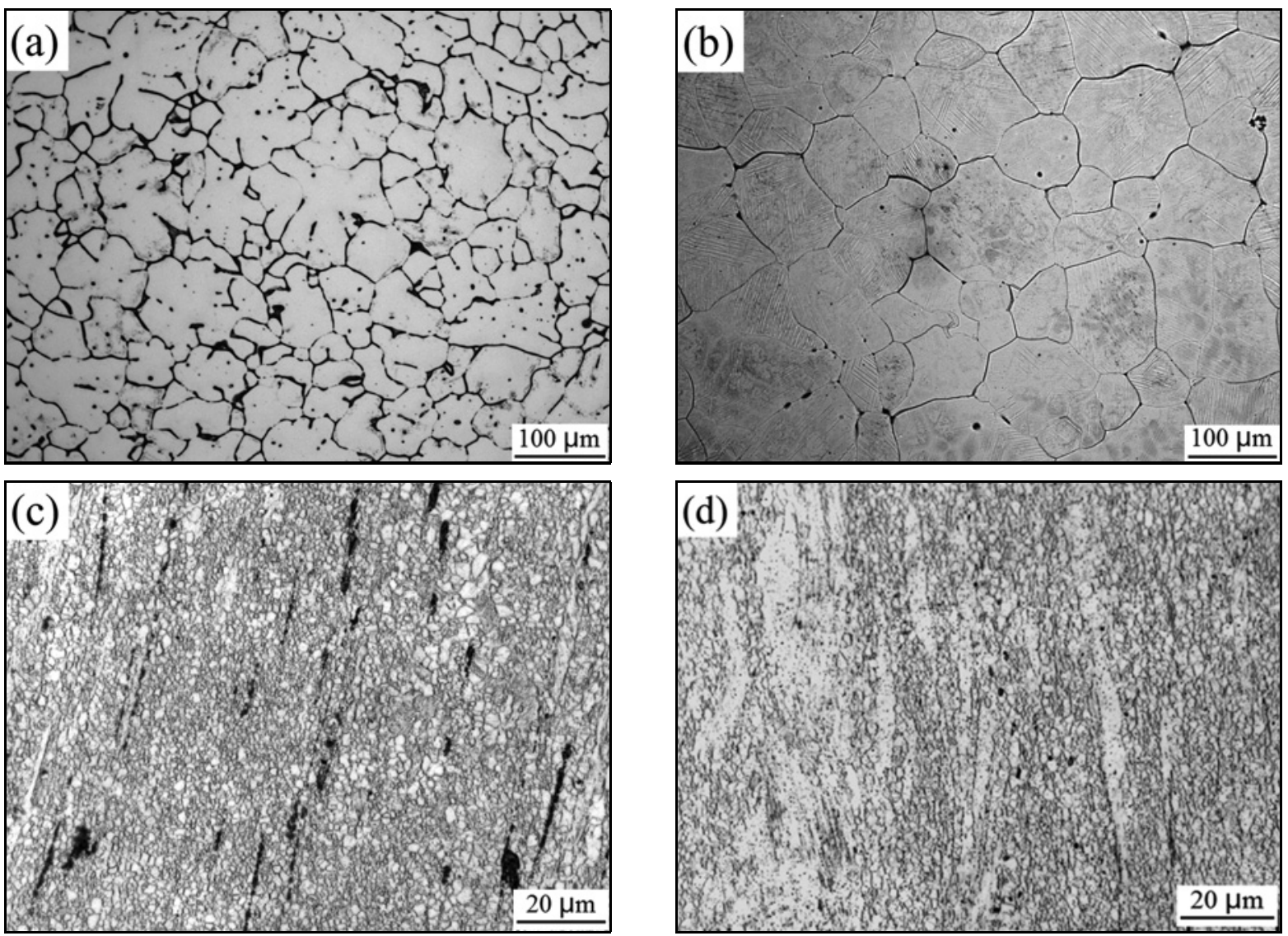

Fig. 1. The optical images of the Mg-2.0Zn-0.5Zr-3.0Gd alloy: (a) as-cast, (b) as-solution, (c) E350, and (d) E360. 

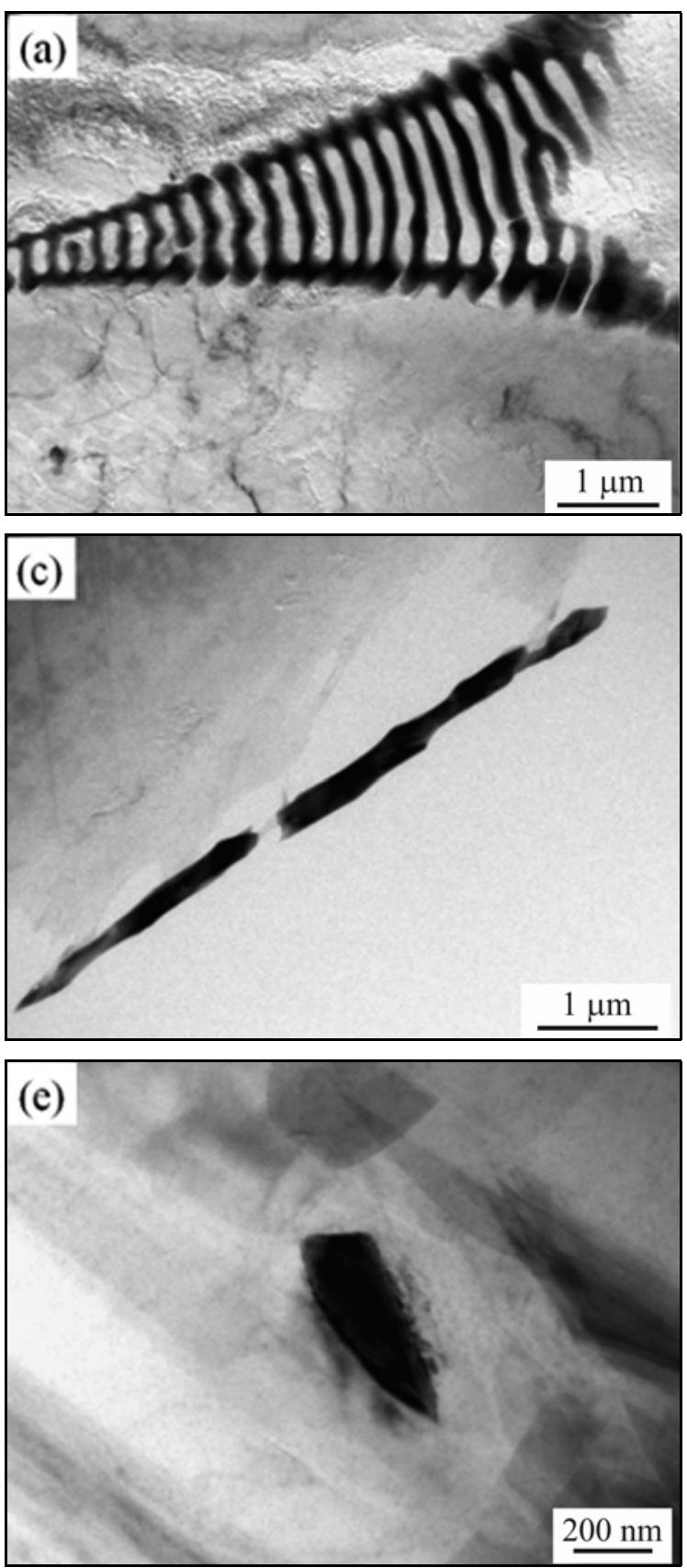
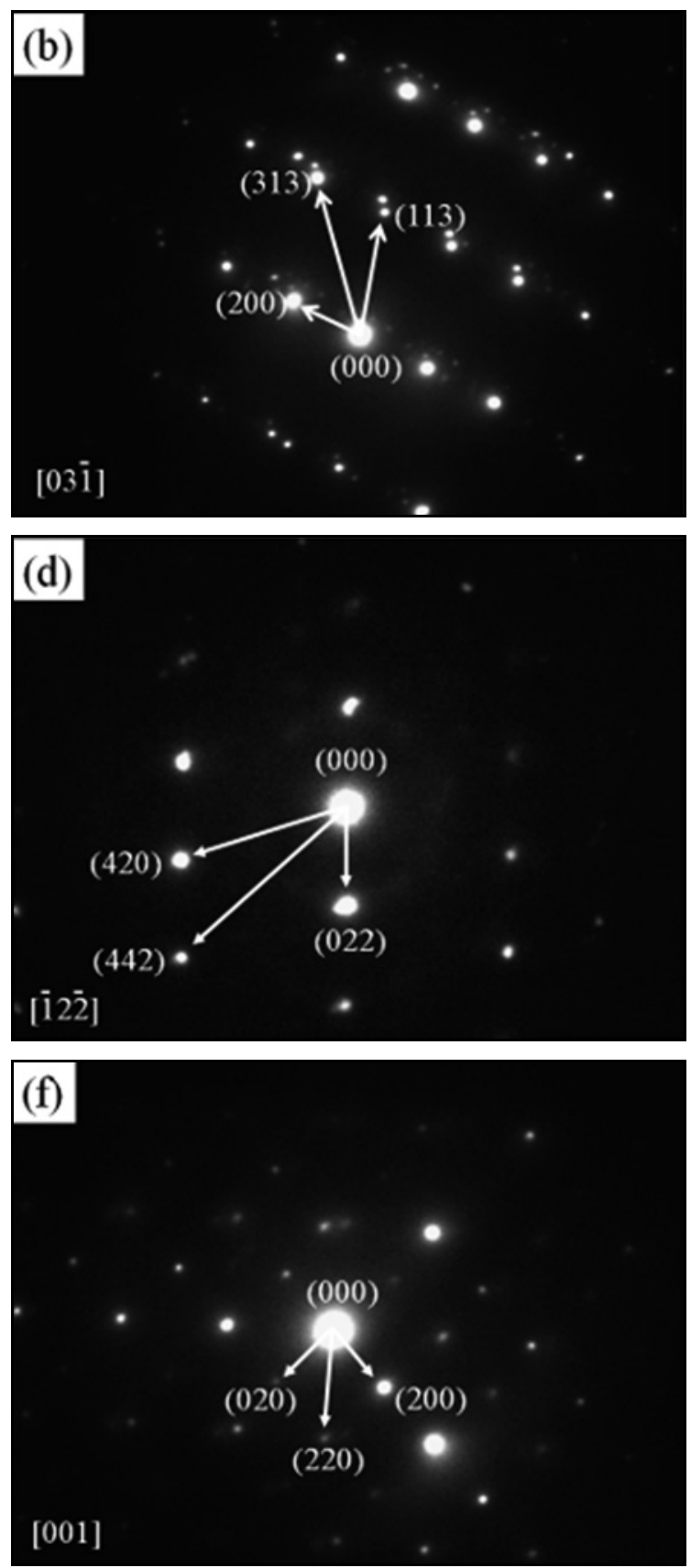

Fig. 2. Microstructure of the as-cast Mg-2.0Zn-0.5Zr-3.0Gd alloy: (a) BF TEM image of fishbone eutectic phase, (b) SAED pattern corresponding to (a), (c) BF TEM image of the long strip eutectic phase, (d) SAED pattern corresponding to (c), (e) BF TEM image of the granular eutectic phase, and (f) SAED pattern corresponding to (e).

PUS) and electronic scanning microscopy (SEM, VEGA3SBH, TESCAN) with Energy Disperse Spectroscopy (EDS). A JEM-2100 transmission electron microscope (TEM) was used for detailed investigations. Thin foils for TEM observation were punched into discs of $3 \mathrm{~mm}$ in diameter, electropolished in an electrolyte of $3 \%$ perchloric acid in ethyl alcohol at $-40{ }^{\circ} \mathrm{C}$ and $0.1 \mathrm{~A}$ after mechanical grinding, and then ion-milled using an ion polishing system (Gatan, model 691).

The extruded rods were machined into tensile spec- imens of $5 \mathrm{~mm}$ gauge diameter and $25 \mathrm{~mm}$ gauge length parallel to the ED. All tensile tests were conducted with an AG-1250KN (SHIMADZU) machine at a speed of $1 \mathrm{~mm} \mathrm{~min}^{-1}$. To control the precision, at least three samples per group were tested. UTS, YS, and EL of tensile specimens were deuced from the stress-strain curves.

Cylindrical samples for the electrochemical test were molded into epoxy resin with only one side of $1 \mathrm{~cm}^{2}$ exposed for the test. Potentiodynamic polarization was carried out at $37 \pm 1^{\circ} \mathrm{C}$ in a beaker containing 
$250 \mathrm{ml}$ of simulated body fluid (SBF) with an electrochemical workstation (Autolab PGSTAT128N) [16]. In the electrochemical test, the three-electrode configuration was adopted. The alloys were used as the working electrode, and a saturated calomel electrode (SCE) and graphite sheet were used as the reference and auxiliary electrodes, respectively. The polarization measurements began after the samples had been dipped in the SBF for $1 \mathrm{~h}$. The potential was scanned from -0.25 to $+0.4 \mathrm{~V}$ relative to the open circuit potential at a scan rate of $1 \mathrm{mV} \mathrm{s}^{-1}$. Three polarization tests were conducted for each condition.

\section{Experimental results}

\subsection{Microstructure}

Figure 1 shows the microstructures of the as-cast, solution-treated, and extruded Mg-2.0Zn-0.5Zr-3.0Gd alloy. The microstructure of the as-cast alloy was composed of equiaxed $\alpha$-Mg grains surrounded by a eutectic phase, as shown in Fig. 1a. The mean grain size of the as-cast alloy was approximately $25 \mu \mathrm{m}$ using the linear intercept method. Figure 1b shows the microstructure of the solution-treated alloy. It can be seen that most of the eutectic regions are dissolved into the $\alpha-\mathrm{Mg}$ matrix. The alloy has a uniform grain structure, and the average grain size is about $150 \mu \mathrm{m}$. Figure 1c shows the optical micrograph of the E350 alloy. Compared to the microstructure of the as-cast alloy, the grain size of E350 was remarkably refined. The area fraction of fine DRXed microstructure and grain size of E350 alloy are estimated to be about $95 \%$ and $\sim 5 \mu \mathrm{m}$, respectively. The eutectic as-cast alloy was mainly changed into black parallel stripes distributed along the ED. The microstructure of the E360 alloy was composed of a lot of fine DRXed grains $(\sim 5 \mu \mathrm{m})$ and a small amount of elongated coarse unrecrystallized (unDRXed) deformed grains, as shown in Fig. 1d.

Figure 2 depicts the bright-field (BF) TEM images and their selected area electron diffraction (SAED) patterns of the as-cast alloy. Network fish-bone shaped eutectic phase on triple boundary junctions, long stripe eutectic phase on the grain boundary, and granular eutectic phase in the interior of the grains are shown in Figs. 2a,c,e, respectively. The corresponding SAED patterns with the electron beam parallel to $[03 \overline{1}],[\overline{1} 2 \overline{1}]$, and [001] are shown in Figs. 2b,d,f, respectively. From the SAED patterns analysis, these eutectic regions are found to be a face-centered cubic (fcc) $\mathrm{Mg}_{3} \mathrm{Gd}$ with $\mathrm{Zn}$ dissolved in the structure. A similar phase distribution is also observed in the $\mathrm{Mg}-\mathrm{Gd}-\mathrm{Zn}$ alloys [17]. The analysis shows that the lattice parameters of three eutectic phases are 0.7246, 0.7243, and $0.7304 \mathrm{~nm}$, respectively. They are smaller than the
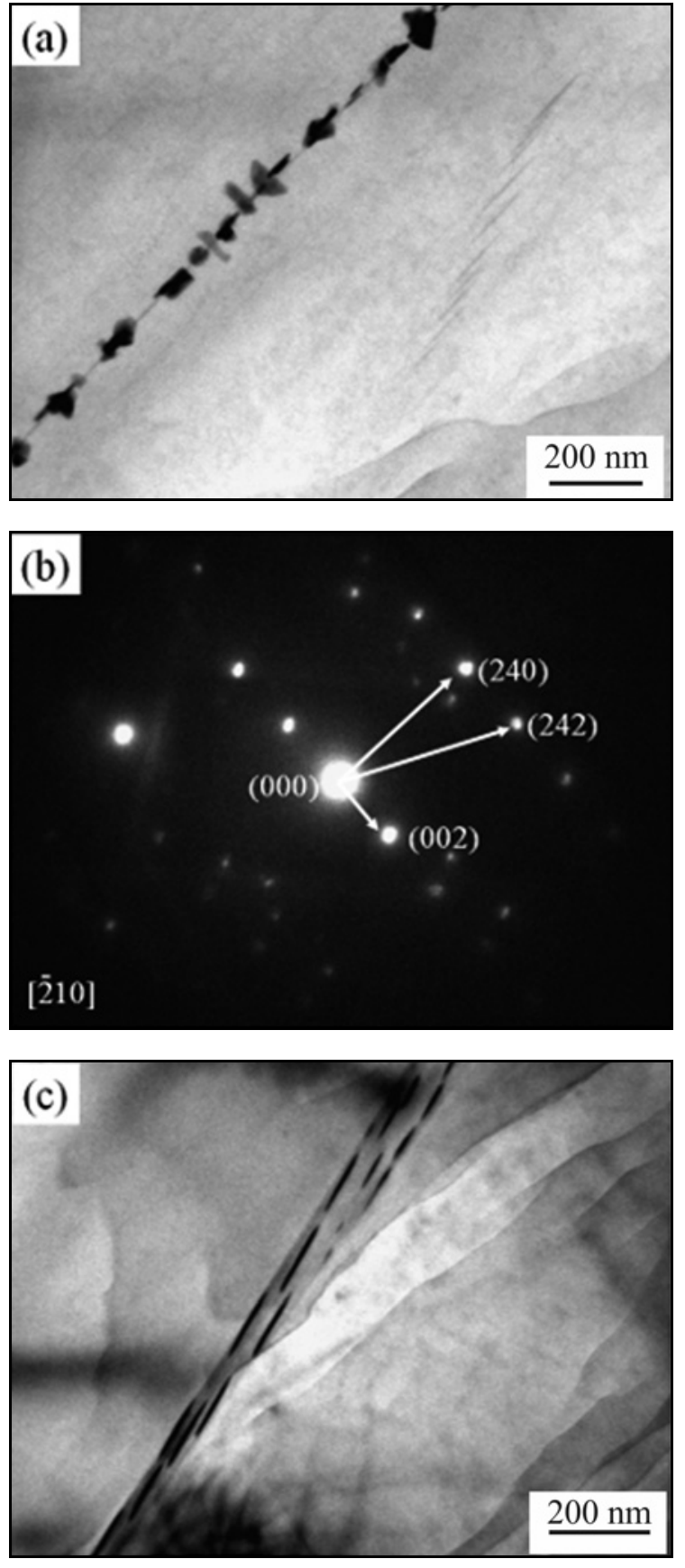

Fig. 3. Microstructure of the solution-treated Mg-2.0Zn-0.5Zr-3.0Gd alloy: (a) BF TEM image of the granular second phase, (b) SAED pattern corresponding to (a), and

(c) BF TEM image of the rod-like second phase.

ideal value of $0.7324 \mathrm{~nm}\left(\mathrm{Mg}_{3} \mathrm{Gd}\right)$. Moreover, small variations in the lattice parameters of $(\mathrm{Mg}, \mathrm{Zn})_{3} \mathrm{Gd}$ phase concerning various $\mathrm{Zn}$ and $\mathrm{Gd}$ contents were observed, as reported by $\mathrm{Xu}$ et al. [18]. The lattice parameter of the $(\mathrm{Mg}, \mathrm{Zn})_{3} \mathrm{Gd}$ phases significantly increases with the $\mathrm{Mg} / \mathrm{Zn}$ ratio in the $(\mathrm{Mg}, \mathrm{Zn})_{3} \mathrm{Gd}$.

Figure 3 presents BF TEM images and their SAED patterns of the solution-treated alloy. The BF image 

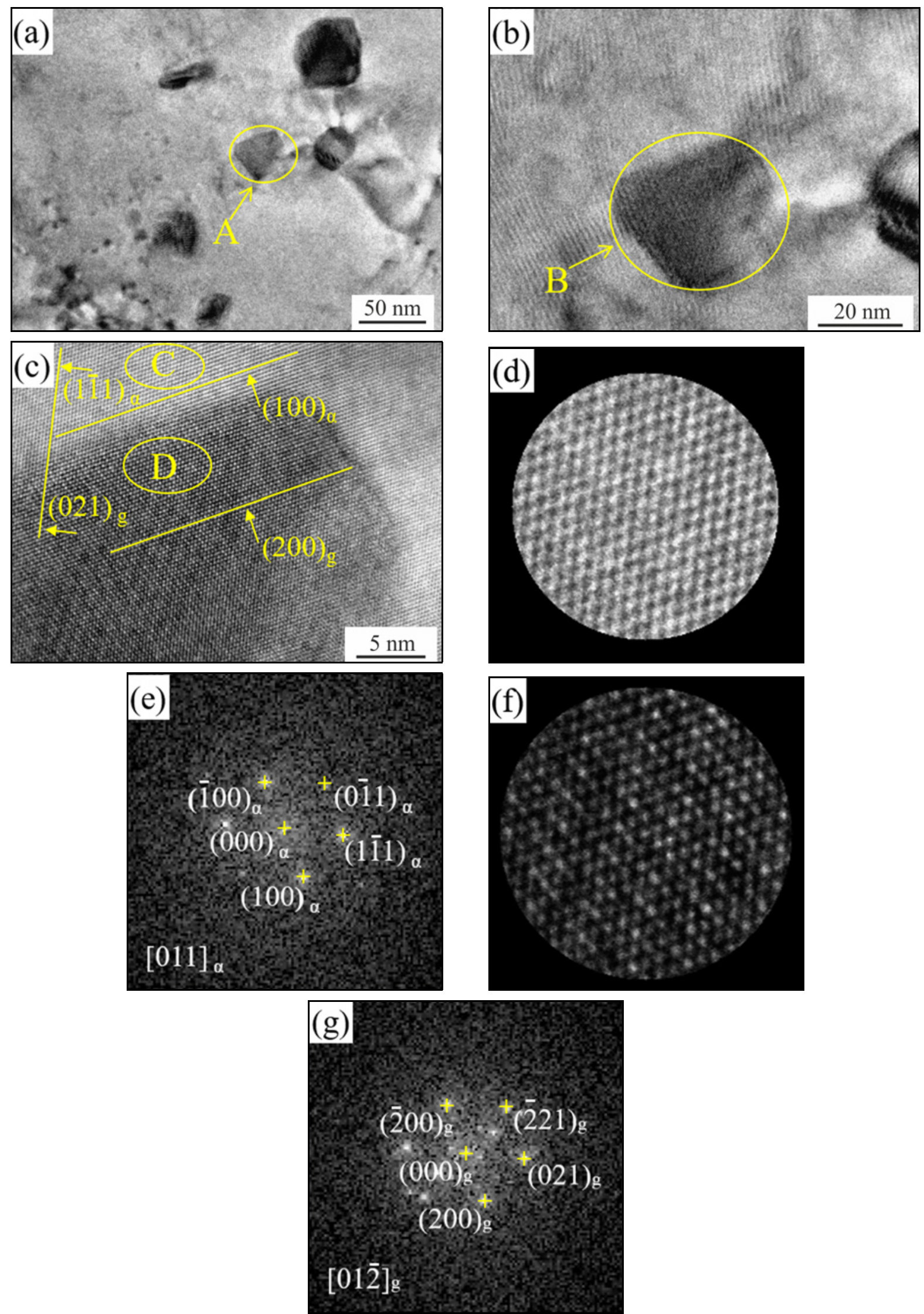

Fig. 4. TEM images of the solution-treated Mg-2.0Zn-0.5Zr-3.0Gd alloy: (a), (b) BF TEM images, (c) HRTEM image, (d) HRTEM image of the C zone, (e) FFT image of (d), (f) HRTEM image of the D zone, and (g) FFT image of (f). 

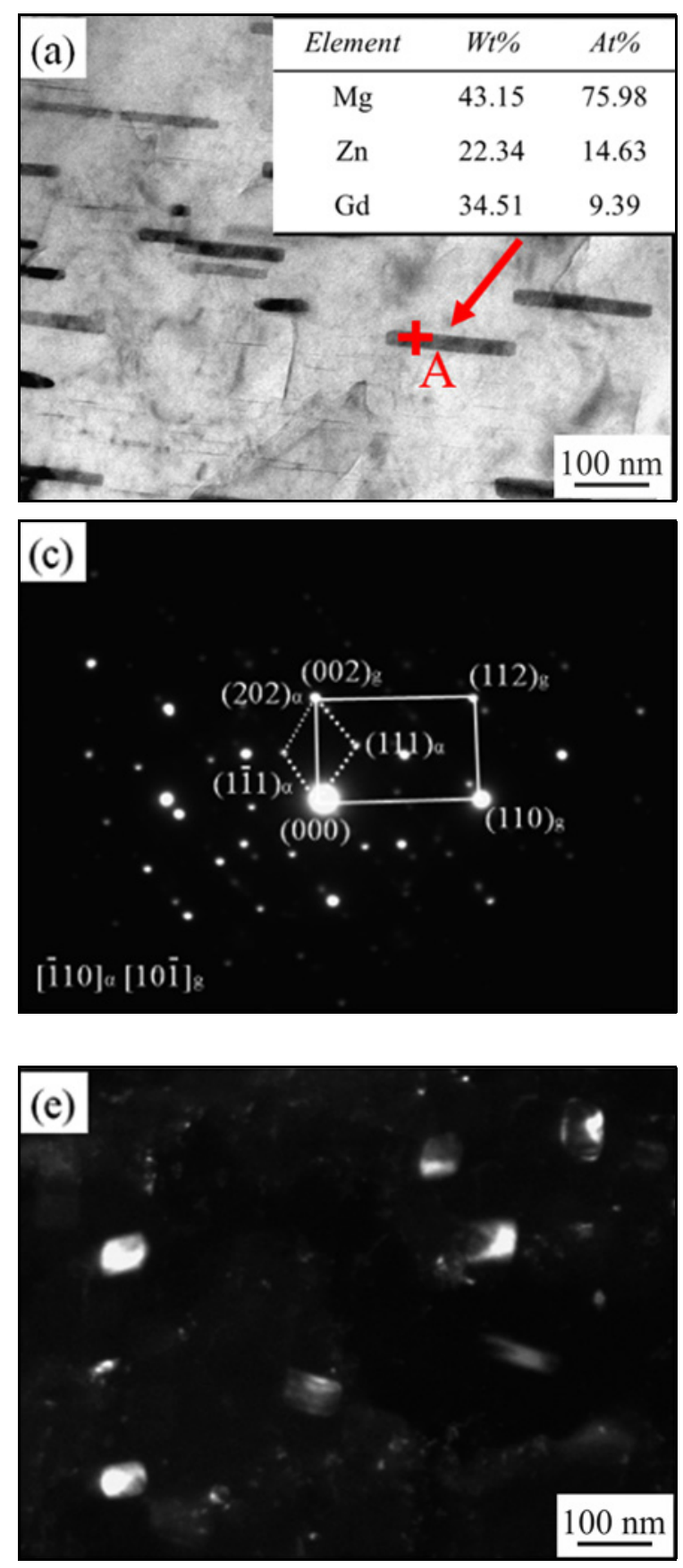
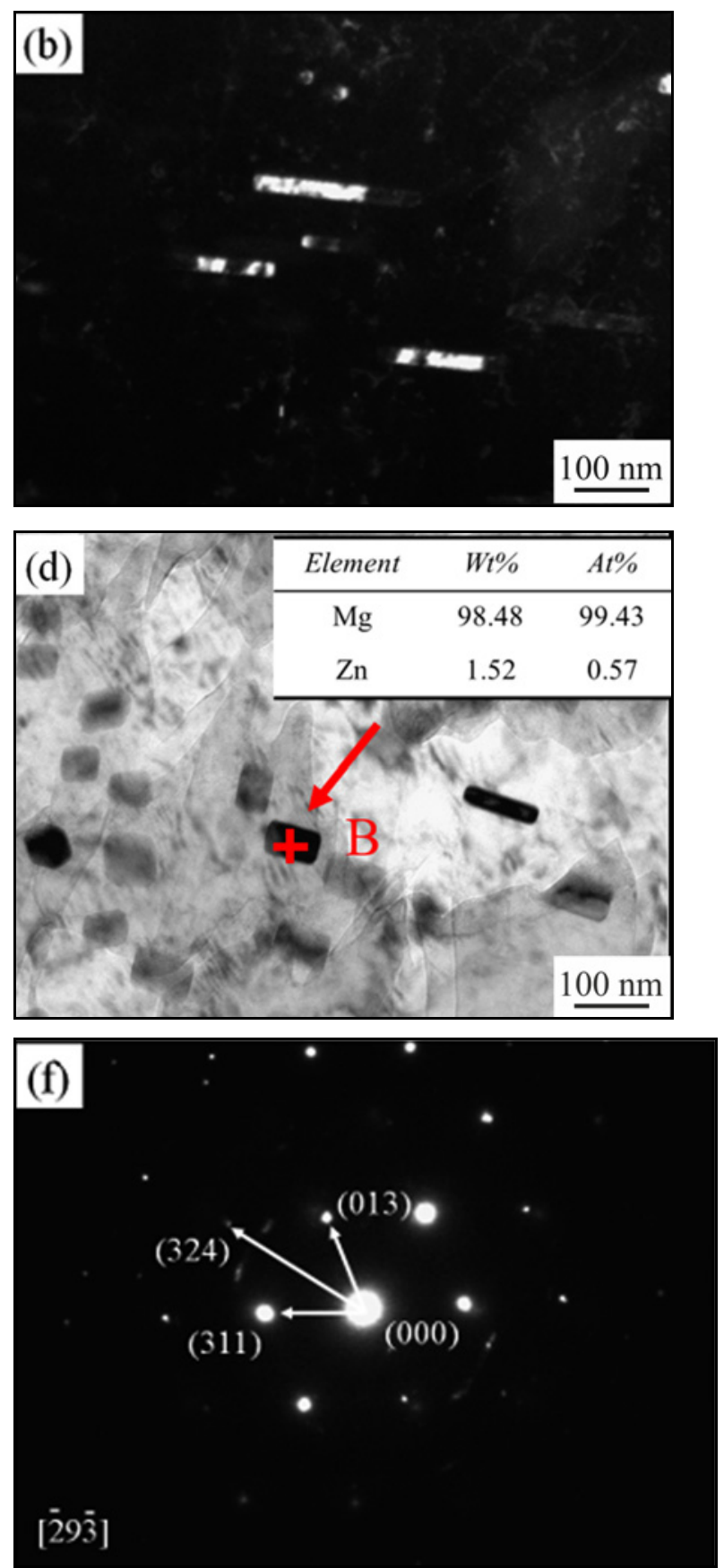

Fig. 5. The microstructure of the E350 alloy: (a) and (b) BF and dark-field TEM images of the rod-like precipitates, (c) corresponding SAED pattern of (a) and (b), (d) and (e) are BF and dark-field images of the granular precipitates, and (f) corresponding SAED pattern of (d) and (e).

of the granular secondary phase and its SAED pattern are shown in Figs. 3a,b, respectively. The SAED pattern corresponding to the granular secondary phase is similar to that of the as-cast alloy with an fcc structure $(\mathrm{Mg}, \mathrm{Zn})_{3} \mathrm{Gd}$. The calculated lattice constant of the $(\mathrm{Mg}, \mathrm{Zn})_{3} \mathrm{Gd}$ phase is $0.7308 \mathrm{~nm}$. The BF image shows dispersed rod-like particles $50-100 \mathrm{~nm}$ in length and 10-20 nm wide (Fig. 3c). The secondary phase becomes less and smaller obvious with decreasing particle size and the increase of the lattice constant, indi- cating that a mass of $\mathrm{Zn}$ and Gd are solid solution into the $\alpha-\mathrm{Mg}$ matrix from the eutectic phase after solution treatment. This is why the large size of the eutectic phase in the as-cast alloy changed into the nanoscale granular or rod-like second phase.

Figure 4 shows the TEM micrographs of the granular secondary phase region of the solution-treated alloy. As shown in Fig. 4a, the secondary phase particles with a size less than $50 \mathrm{~nm}$ are distributed in the $\alpha-\mathrm{Mg}$ matrix. Figure $4 \mathrm{~b}$ is an enlargement of region 
Table 1. Mechanical properties of the as-cast, as-solution, E350 and E360 alloys

\begin{tabular}{lrrrr}
\hline Material & \multicolumn{1}{c}{ As-cast } & As-solution & E350 & E360 \\
\hline UTS (MPa) & $204.2 \pm 3.2$ & $215.4 \pm 2.6$ & $246.9 \pm 3.4$ & $249.3 \pm 3.2$ \\
YS (MPa) & $155.2 \pm 2.5$ & $175.3 \pm 3.3$ & $214.4 \pm 3.2$ & $227.9 \pm 2.8$ \\
EL (\%) & $10.6 \pm 0.6$ & $12.1 \pm 0.5$ & $26.7 \pm 1.1$ & $29.8 \pm 0.8$ \\
\hline
\end{tabular}

A in Fig. 4a, and Fig. 4c is the HRTEM image of region $\mathrm{B}$ in Fig. 4b. The fast Fourier transform (FFT) was carried out in the $\mathrm{C}$ region of the matrix and $\mathrm{D}$ region of secondary phase region in Fig. 4c. The magnified HRTEM images and corresponding FFT images are depicted in Figs. 4e,f,g. The $\alpha$-Mg matrix oriented along $[011]_{\alpha}$ is identified from the SAED of Fig. 4e, which is the FFT from Fig. 4d. The secondary phase of $(\mathrm{Mg}, \mathrm{Zn})_{3} \mathrm{Gd}$ phase is oriented along $[0 \overline{1} 2]_{\mathrm{g}}$ as deduced from SAED of Fig. $4 \mathrm{~g}$ (the FFT from Fig. 4f), identified as a hexagonal structure with $a=0.64 \mathrm{~nm}$ and $c=0.51 \mathrm{~nm}$ [19]. The HRTEM image of Fig. 4c, FFT images of Figs. 4g,e illustrate the orientation relationship between the $(\mathrm{Mg}, \mathrm{Zn})_{3} \mathrm{Gd}$ phase and $\alpha$-Mg matrix: it appears that $(100)_{\alpha} \|(200)_{\mathrm{g}}$, $(1 \overline{1} 1)_{\alpha}\left\|(021)_{\mathrm{g}},(0 \overline{1} 1)_{\alpha}\right\|(\overline{2} 21)_{\mathrm{g}},[011]_{\alpha} \|[0 \overline{1} 2]_{\mathrm{g}}$. The lattice mismatch was calculated according to $\delta=2\left(X_{\mathrm{A}}-X_{\mathrm{B}}\right) /\left(X_{\mathrm{A}}+X_{\mathrm{B}}\right)[20]$. While $d(1 \overline{1} 1)_{\alpha}=$ $0.245 \mathrm{~nm}$ and $d(021)_{\mathrm{g}}=0.259 \mathrm{~nm}$, the calculated mismatch $\delta_{1}$ is $5.4 \%$, which, being greater than $5 \%$, leads to an incoherent interface [21]. These results indicate that the $(\mathrm{Mg}, \mathrm{Zn}){ }_{3} \mathrm{Gd}$ phase has a semi-coherent relationship with the $\alpha$-Mg matrix.

Figure 5 illustrates the TEM micrographs of the E350 alloy. In Fig. 5a, the BF image shows loosely dispersed rod-like particles with 50-300 nm length and 20-30 nm width, and these particles (marked A) are mainly composed of $\mathrm{Mg}, \mathrm{Zn}$, and Gd elements by EDS analysis. Rod-like particles are oriented along the ED in the dark field image in Fig. 5b. Two kinds of lattice structures were derived from the SAED patterns (Fig. 5c). One was the hexagonal close-packed lattice of the $\alpha-\mathrm{Mg}$ matrix, and another was the fcc structure of the rod-like phases. Based on the EDS and SAED analysis, the rod-like phases were identified to be made of $(\mathrm{Mg}, \mathrm{Zn})_{3} \mathrm{Gd}$ phase $(a=0.726 \mathrm{~nm})$, similar to those observed in the as-cast alloy (see Fig. 2). Some nanoscale elliptical particles composed of $\mathrm{Mg}$ and $\mathrm{Zn}$ elements (marked B) are seen randomly distributed within the $\alpha$-Mg matrix (Figs. 5d,e). Based on SAED (Fig. 5f), the elliptical particles appear to have a primitive cubic lattice structure with a lattice constant of $0.8571 \mathrm{~nm}$. According to the EDS and SAED analysis, it was identified as $\mathrm{Mg}_{2} \mathrm{Zn}_{11}$ with their axis parallel to the $[\overline{2} 9 \overline{3}]$ direction. The $\mathrm{Mg}_{2} \mathrm{Zn}_{11}$ phase has not been found in the as-cast and solution-treated alloy. This may be due to partial $\mathrm{Zn}$ element precipitation from $(\mathrm{Mg}, \mathrm{Zn})_{3} \mathrm{Gd}$, and then $\mathrm{Zn}$ bonds with the $\mathrm{Mg}$ to form
$\mathrm{Mg}_{2} \mathrm{Zn}_{11}$ during the extrusion process.

Figures 6a,b,c show typical TEM BF images of the E350 alloy. It can be seen that a certain amount of granular precipitates is distributed in the interior of DRXed grains or some DRXed grains boundary, indicating that these granular precipitates were effective to hinder the movement of dislocations when the basal slip occurred. Besides, high density dislocations were observed within individual DRXed grains. Figures 6d,e,f show typical TEM BF images of the E360 alloy. It can be seen that the rod-like form of $(\mathrm{Mg}$, $\mathrm{Zn})_{3} \mathrm{Gd}$ phase and elliptical $\mathrm{Mg}_{2} \mathrm{Zn}_{11}$ phase particles were mainly distributed in different regions of the $\alpha$-Mg matrix, and fine second phase particles were dynamically precipitated at the DRXed grain boundaries and within the grains.

\subsection{Mechanical properties}

The engineering stress-strain curves of the ascast, solution-treated, and as-extruded alloys tested at room temperature and corresponding UTS, YS, and EL are summarized in Table 1. The mechanical properties of the different alloys ordered from least to most significant are as-cast $<$ solution-treated $<$ E350 $<$ E360 alloys. The E360 alloy exhibits the highest UTS of $249.3 \pm 3.2 \mathrm{MPa}$, YS of $227.9 \pm 2.8 \mathrm{MPa}$, and EL of $29.8 \pm 0.8 \%$.

\subsection{Fracture characteristics}

Figure 7 shows the fracture surface images of the as-cast, solution-treated, and as-extruded alloys. As shown in Fig. 7a, there are some large-sized cleavage facets and deep cracks on the fracture surface of the as-cast alloy. For the solution-treated alloy, small sized cleavage planes and a small number of shallow dimples dominate the fracture surface. The fracture surface images indicate that the general fracture regime transforms from cleavage fracture (Fig. 7a) to quasicleavage fracture (Fig. 7b). The tensile fracture surface of the E350 alloy in Fig. 7c consists of uniform small dimples and short and small tearing edges, indicating it as a ductile fracture mode. For the E360 specimen, the fracture surface with large and deep dimples exhibits a better ductility, as shown in Fig. 7d. It indicates more dislocation pile-ups before the formation of the cracks. 

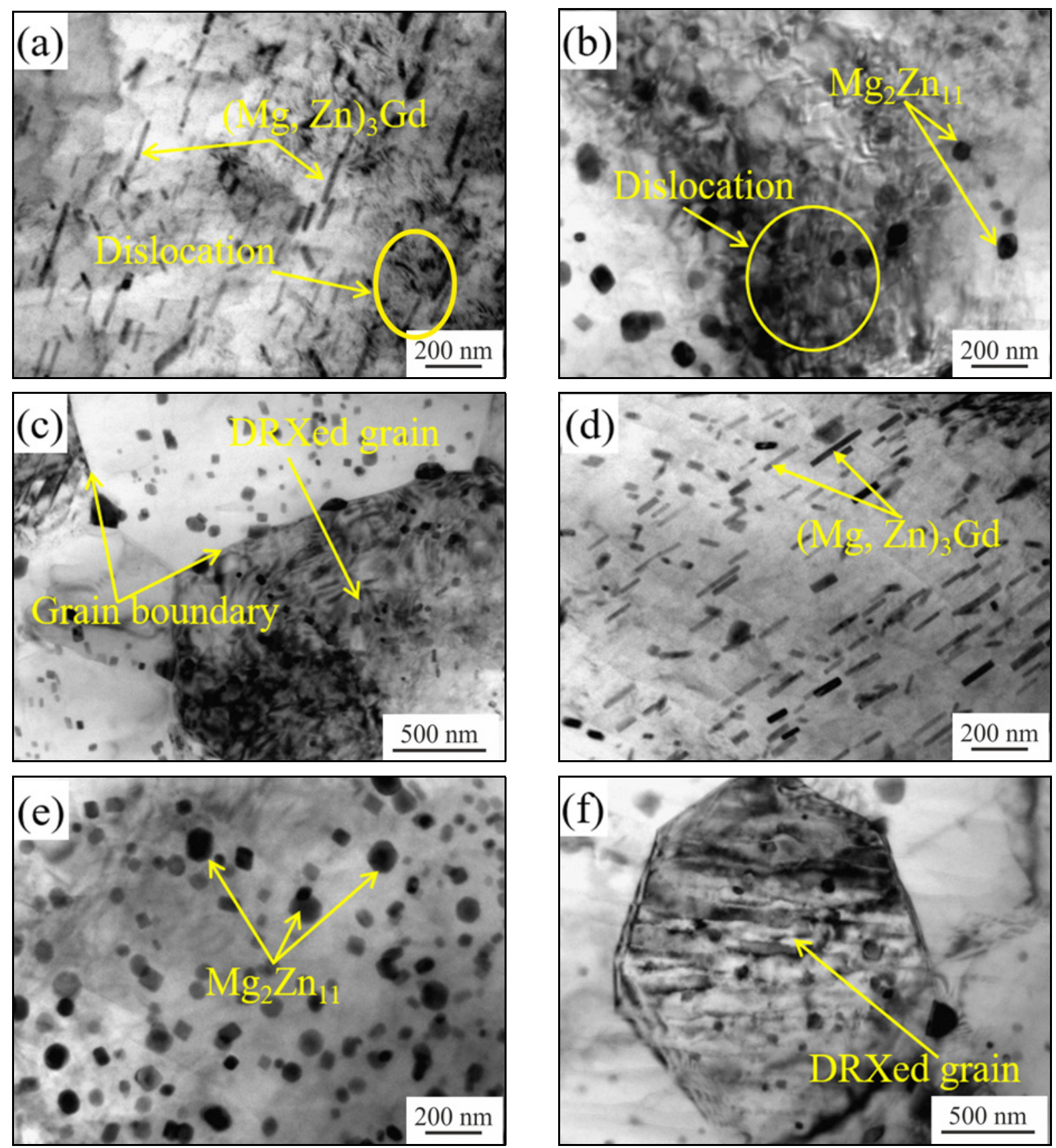

Fig. 6. Typical TEM BF images of the E350 and E360 alloys: (a), (b), and (c) E350; (d), (e), and (f) E360.

\subsection{Polarization curves}

Figure 8 presents the typical potentiodynamic polarization behavior of the as-cast, solution-treated, and as-extruded alloys in SBF. The corrosion potential $\left(E_{\text {corr }}\right)$, corrosion current density $\left(I_{\text {corr }}\right)$, and corrosion rate $\left(P_{\mathrm{i}}\right)$ are derived directly from these polarization curves by Tafel region extrapolation. The corresponding results are summarized in Table 2. Generally, the cathodic polarization curves were ascribed to the reduction of water mainly occurred near the cathode phase. From Fig. 8, the cathodic branch of the specimen E350 is a little higher than that of other alloys; it may be caused by the difference of formation and distribution of the second phase. Compared with other alloys, the coarse second phase in the E350 alloy becomes fine granular particles uniformly distributed after extrusion treatment, increasing the contact area between the cathode phase and the corrosive medium. Under the condition of cathode polarization, the increased contact area of the cathode phase is helpful in improving the electrochemical reaction kinetics and the current density of the cathode area [22]. A similar phenomenon is also reported by other research [23]. 

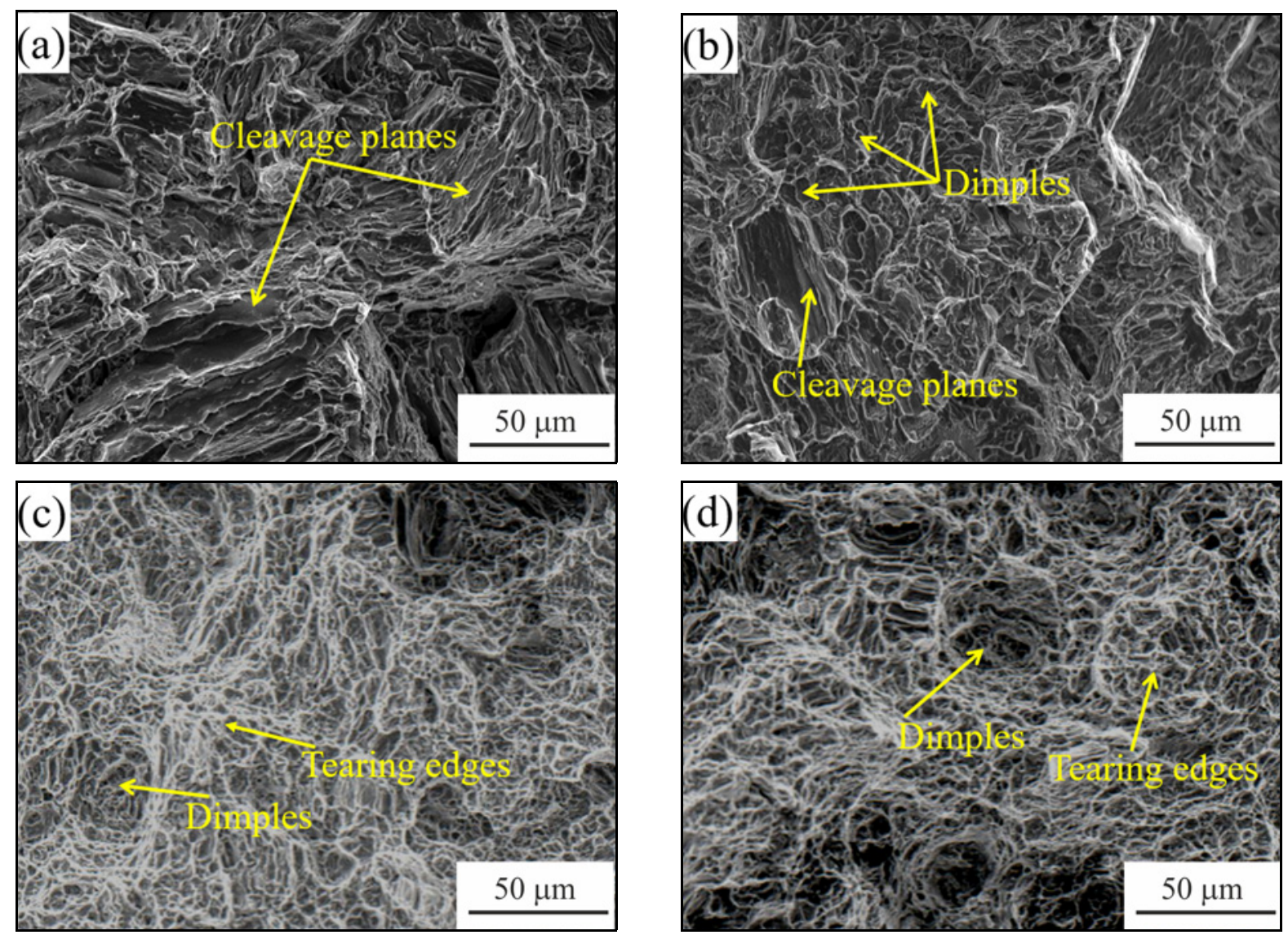

Fig. 7. SEM images of fracture surfaces of the Mg-2.0Zn-0.5Zr-3.0Gd alloys: (a) as-cast, (b) as-solution, (c) E350, and (d) E360.

The anode polarization curves are mainly related to the dissolution of $\mathrm{Mg}$, and thus reflecting the corrosion rate of the alloy. As shown in Fig. 8, the E360 alloy owns the most positive $E_{\text {corr }}$ of $-1.3932 \pm 0.0034 \mathrm{~V}$

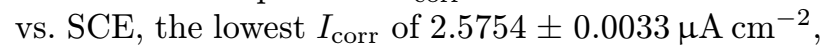
and the minimal $P_{\mathrm{i}}$ of $0.1159 \pm 0.0027 \mathrm{~mm} \mathrm{y}^{-1}$. The corrosion resistance of tested samples can be ranked in the following order: E360 > E350 > solution-treated $>$ as-cast alloys.

\section{Discussion}

\subsection{Microstructure evolution}

Compared with the microstructure of as-cast and solution-treated alloys (Figs. 1a,b), the grain size of as-extruded alloys is refined remarkably, indicating that during extrusion, DRXed occurs in E350 and E360 alloys. The results from TEM in Figs. 5, 6 show that precipitation in the E350 and E360 alloys mainly consists of a large number of rod-like form of $(\mathrm{Mg}, \mathrm{Zn})_{3} \mathrm{Gd}$ phase and elliptical $\mathrm{Mg}_{2} \mathrm{Zn}_{11}$ phase. The change of size and shape of $(\mathrm{Mg}, \mathrm{Zn})_{3} \mathrm{Gd}$ phase from as-cast and solution-treated to as-extruded alloys in-

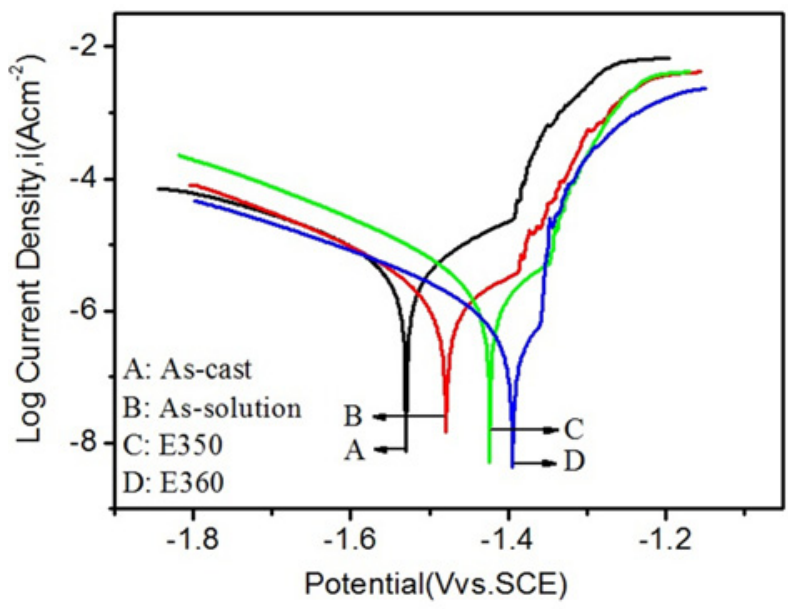

Fig. 8. Potentiodynamic polarization curves of the $\mathrm{Mg}$ $-2.0 \mathrm{Zn}-0.5 \mathrm{Zr}-3.0 \mathrm{Gd}$ alloys after immersion in SBF for $1 \mathrm{~h}$.

dicates that the rod-like form of $(\mathrm{Mg}, \mathrm{Zn})_{3} \mathrm{Gd}$ phase is the dissolution and reprecipitation of the original $(\mathrm{Mg}, \mathrm{Zn})_{3} \mathrm{Gd}$ phase during the extrusion process. For $\mathrm{Mg}_{2} \mathrm{Zn}_{11}$ phase, the atomic radius of $\mathrm{Zn}(\sim 0.139 \mathrm{~nm})$ is smaller than the $\mathrm{Mg}(\sim 0.160 \mathrm{~nm})$. This enables easy 
Table 2. $E_{\text {corr }}, I_{\text {corr }}$, and $P_{\mathrm{i}}$ of as-cast, as-solution, E350 and E360 alloys derived from the polarization curves

\begin{tabular}{lrrrr}
\hline Material & \multicolumn{1}{c}{ As-cast } & \multicolumn{1}{c}{ As-solution } & \multicolumn{1}{c}{ E350 } & E360 \\
\hline$E_{\text {corr }}(\mathrm{V} \mathrm{vs.} \mathrm{SCE})$ & $-1.5312 \pm 0.0029$ & $-1.4801 \pm 0.0031$ & $-1.4753 \pm 0.0031$ & $-1.3932 \pm 0.0034$ \\
$I_{\text {corr }}\left(\mu \mathrm{A} \mathrm{cm}^{-2}\right)$ & $7.6861 \pm 0.0026$ & $4.0419 \pm 0.0029$ & $3.9588 \pm 0.0030$ & $2.5754 \pm 0.0033$ \\
$P_{\mathrm{i}}\left(\mathrm{mm} \mathrm{y}^{-1}\right)$ & $0.3432 \pm 0.0031$ & $0.1831 \pm 0.0031$ & $0.1786 \pm 0.0030$ & $0.1159 \pm 0.0027$ \\
\hline
\end{tabular}

diffusion of $\mathrm{Zn}$ in the $\mathrm{Mg}$ matrix at high extrusion temperatures. The alloy is accompanied by increased vibration energy and diffusion coefficient of the atoms during heating and extrusion, as well as many defects such as holes, subgrain boundaries, and dislocations. Therefore, the diffusion and dissolution of $\mathrm{Zn}$ atoms easily occurred at grain boundaries and phase boundaries during extrusion. The solid solubility of $\mathrm{Zn}$ in the $\alpha$-Mg matrix decreases with the temperature decrease. In the poor Gd region, during the cooling process, the precipitated $\mathrm{Zn}$ first forms a smaller $\mathrm{Mg}_{2} \mathrm{Zn}_{11}$ nucleus with $\mathrm{Mg}$. With the extension of time, the precipitated phase of $\mathrm{Mg}_{2} \mathrm{Zn}_{11}$ increases with the continuous diffusion of $\mathrm{Zn}$ atoms through the grain boundary. Due to the transient extrusion process, the precipitated phase of $\mathrm{Mg}_{2} \mathrm{Zn}_{11}$ is finally distributed in the $\alpha-\mathrm{Mg}$ matrix by fine, diffused elliptical particles.

As seen in Fig. 1a and Fig. 2, many $(\mathrm{Mg}, \mathrm{Zn})_{3} \mathrm{Gd}$ regions exist in the as-cast alloy. Obviously, $(\mathrm{Mg}$, $\mathrm{Zn})_{3} \mathrm{Gd}$ phase particles play an important role in promoting DRX and refining DRXed grains (Fig. 1c). It is well known that secondary phase particles play a significant role in DRX. Coarse constituent secondary phase particles can accelerate DRX by particle stimulated nucleation due to a large amount of stored energy in the deformation zone [24].

On the other hand, the broken secondary phase particles can also act as nucleation sites for DRX during hot extrusion and play a role in promoting DRX. As an alloying element, Gd can effectively reduce the stacking fault energy of the $\alpha-\mathrm{Mg}$ matrix [25]. The low stacking fault energy will promote the formation of wider stacking faults, which makes the dislocation constriction and cross slip more difficult [26]. For Mg$2.0 \mathrm{Zn}-0.5 \mathrm{Zr}-3.0 \mathrm{Gd}$ alloy, it is thus difficult to form subgrain structures during deformation; instead, deformation store energy increases to a high level, and local dislocation density becomes large enough to overcome the capillary term to allow the formation of new grains [27]. Therefore, DRX becomes easier when $3.0 \%$ of $\mathrm{Gd}$ is added to the $\mathrm{Mg}-2.0 \mathrm{Zn}-0.5 \mathrm{Zr}$ alloys. Generally, the dislocations are easily generated during hot extrusion, resulting in a certain amount of residual dislocations in the E350 alloy (Figs. 6a,b,c). As shown in Fig. 1c, when the extrusion temperature is $350^{\circ} \mathrm{C}$, the fine and uniform DRX grain microstructures are formed. Besides, part of the undissolved $(\mathrm{Mg}, \mathrm{Zn})_{3} \mathrm{Gd}$ phase particles is broken up and forms a band structure along the ED.
By contrast, fine second phase particles tend to hinder boundary motion and slow down recrystallization and grain growth through a Zener drag effect [28]. As seen in Fig. 1b and Figs. 3-5, a small number of nanoscale particles (particle size $<0.5 \mu \mathrm{m}$ ) exist in the solution-treated alloy. It has been reported in the literature that fine particles smaller than $1 \mu \mathrm{m}$ contribute to restraining recrystallization rather than promoting it by impeding the formation of the lattice curvatures necessary for nucleation via boundary pinning [29]. As shown in Fig. 4, the secondary phase particles in solution-treated alloy have a semicoherent relationship with the $\alpha$-Mg matrix. The secondary phase particle/matrix character also affects DRX behavior. DRX takes place less easily in alloys containing coherent precipitated particles than in alloys with incoherent particles [30]. Recrystallization kinetics accelerates with increasing deformation temperature $[26,31]$. Therefore, due to the difference of microstructure between the as-cast alloy before extrusion and the alloy after solution treatment, the temperature of complete dynamic recrystallization that occurs during the extrusion process is different.

\subsection{Microstructure influence on mechanical properties}

The cleavage planes and dominant tearing ridges, which are typical of brittle fracture, can be seen on the tensile fracture surface of the as-cast alloy (Fig. 7a). Rather large secondary phase regions exist within the matrix, resulting in poor mechanical properties. As shown in Fig. 7b, the tensile fracture surface of the solution-treated alloy consisted of cleavage planes, tearing ridges, and small dimples. It is a mixed type with cleavage fracture and quasi-cleavage fracture. The mechanical properties of the solutiontreated alloy are slightly improved due to solid solution strengthening and precipitation strengthening. As seen in Fig. 4, due to the semi-coherent interface relationship of the second phase with the $\alpha-\mathrm{Mg}$ matrix, the second phases formed after solution treatment contribute to the excellent plasticity and high strength.

By hot extrusion, most of the large-sized secondary phases in the as-cast alloy disappeared, and microcracks would not initiate easily by the fracture of eutectic particles. More importantly, the predominant 
elliptical $\mathrm{Mg}_{2} \mathrm{Zn}_{11}$ and rod-like ( $\left.\mathrm{Mg}, \mathrm{Zn}\right)_{3} \mathrm{Gd}$ precipitates acted as strong pinning points hindering $(001)_{\alpha}$ glide, which could reduce the mobility of dislocations in the grain [32]. Thus, the room temperature mechanical properties of the as-extruded alloy have significantly been improved under the combined action of fine grain strengthening and secondary phase precipitation strengthening.

The structures of the fracture surface and failure mode are quite similar for E350 and E360 alloys. The fracture surfaces consist mainly of a large number of dimples and tearing edges with the features of plastic fracture. The grain refinement caused by hot extrusion can make the migration, slip, and rotation of grain boundary become easier, as the cracking direction can frequently change during the crack propagation. Hence, the fracture mode of the E350 and E360 alloys is a ductile fracture.

The excellent ductility of the E350 and E360 alloys can be mainly attributed to the following 3 factors: (1) Grain refinement achieved by hot extrusion gives high deformation coordination capability, which can enhance the ductility; (2) the weakened recrystallization basal texture facilitates the basal slip, which can also improve the ductility [25]; (3) the finer grains contribute to non-basal slip system activations which can enhance the ductility of the alloy [33]. The E360 alloy has higher mechanical properties relative to E350 alloy. This may be due to the parallel stripes distributed along the ED of the second phase in the E350 alloy. These second phase stripes may become the source of cracks during a tensile strength test.

\subsection{Grain refinement impacts on corrosion behavior}

In the present study, the as-cast alloy is mainly composed of equiaxed $\alpha-\mathrm{Mg}$ grains and coarse $(\mathrm{Mg}$, $\mathrm{Zn})_{3} \mathrm{Gd}$ phase at the grain boundaries (Fig. 1). Although the electrochemical potential of $(\mathrm{Mg}, \mathrm{Zn})_{3} \mathrm{Gd}$ phase has not been reported to date, it is reported that the $(\mathrm{Mg}, \mathrm{Zn})_{3} \mathrm{Gd}$ phase is nobler than the $\alpha-\mathrm{Mg}$ matrix [34]. These noble $(\mathrm{Mg}, \mathrm{Zn})_{3} \mathrm{Gd}$ phase precipitates with larger size, and can cause micro-galvanic corrosion in the as-cast condition and lead to high corrosion rate and localized corrosion [35].

The micro-galvanic effect due to the secondary phase reduces the corrosion resistance of $\mathrm{Mg}-\mathrm{RE}-\mathrm{Zn}$ alloy, and the corrosion properties improve drastically when the secondary phases are dissolved into the $\mathrm{Mg}$ matrix by solution treatment [36]. Compared with the micro-sized ( $\mathrm{Mg}, \mathrm{Zn})_{3} \mathrm{Gd}$ phase particles in the as-cast alloy, the nano-sized $(\mathrm{Mg}, \mathrm{Zn}){ }_{3} \mathrm{Gd}$ phase particles in the solution-treated alloy are much smaller. The galvanic corrosion rate decreased sharply with the decrease of the volume ratio of the cathode to anode, and the dissolution rate of the $\mathrm{Mg}$ matrix around the nanometer second phase decreased significantly [37]. Therefore, the possible micro galvanic corrosion between the nano-sized $(\mathrm{Mg}, \mathrm{Zn})_{3} \mathrm{Gd}$ phase particles and the $\alpha$-Mg matrix is inhibited because of the small size of the $(\mathrm{Mg}, \mathrm{Zn})_{3} \mathrm{Gd}$ phase. The alloy elements dissolve in the $\alpha$-Mg matrix, which can increase the $E_{\text {corr }}$ and improve the corrosion resistance of the alloy. Consistent with the result of Table 2, the solution-treated alloy has a better corrosion resistance than as-cast alloy.

In a passivating environment, grain refinement leads to an enhancement in corrosion resistance, while this trend turns into the opposite in a non-passivating active environment [38]. In an SBF environment which elicits an inert reaction, the grain refinement is likely to improve corrosion resistance in three ways of (1) physical corrosion barriers from grain boundaries [39], (2) accelerating the passivation kinetics, and (3) reduce the intensity galvanic couple between grain boundary and grain interior [40]. Therefore, the grain refinement leads to the formation of closely spaced electrochemical batteries of cathodic-anodic regions. The difference between the rates of cathodic and anodic reactions is thus expected to decrease significantly, which leads to better corrosion uniformity and lower rates [41]. The grain boundary area increases considerably with reduced grain size; therefore, the corrosion rate of the E350 and E360 alloys shows considerable reduction over as-cast and solution-treated alloys. The equilibrium potential in the vicinity of dislocation is reduced, which with a higher density of dislocation, probably accelerates the anodic metal dissolution [42]. Compared with the E360 sample, a high density of dislocation and parallel stripes of the secondary phase are present in the E350 sample. Still, the grain size did not change significantly, resulting in a relatively high corrosion rate.

The above results, therefore, show that grain refinement of $\mathrm{Mg}$ alloys by hot extrusion is an alternative means to improve the mechanical strength and corrosion resistance compared to the known alloying method. Hence, grain refined solution-treated Mg-2.0Zn-0.5Zr-3.0Gd alloy could potentially have useful benefits when used as metallic biomaterial.

\section{Conclusions}

The effect of the hot extrusion on microstructure, mechanical properties, and corrosion resistance of the as-cast and solution-treated Mg-2.0Zn-0.5Zr-3.0Gd alloy have been investigated. The following conclusions are drawn:

1. The microstructure of as-cast and solid solution alloys is mainly composed of equiaxed $\alpha-\mathrm{Mg}$ matrix and $(\mathrm{Mg}, \mathrm{Zn})_{3} \mathrm{Gd}$ precipitates with different sizes. In solid solution alloys, the nanoscale granular $(\mathrm{Mg}$, 
Zn $)_{3}$ Gd precipitates have a semi-coherent relationship with the $\alpha-\mathrm{Mg}$ matrix.

2 . The temperature of complete dynamic crystallization of solid solution extruded alloy is about $360^{\circ} \mathrm{C}$, which is higher than that of as-cast extruded alloy. The extruded alloys are composed of massive refined DRXed grains and a very tiny amount of elongated coarse unDRXed deformed grains. There are many nano-rod-like $(\mathrm{Mg}, \mathrm{Zn})_{3} \mathrm{Gd}$ precipitates, and elliptical $\mathrm{Mg}_{2} \mathrm{Zn}_{11}$ precipitates in the two extruded alloys.

3 . The mechanical properties and corrosion resistance of tested samples can be ranked in the following order: E360 > E350 > solution-treated > as-cast alloys. The E360 alloy exhibits the highest UTS of $249.3 \pm 3.2 \mathrm{MPa}$, YS of $227.9 \pm 2.8 \mathrm{MPa}$, and EL of $29.4 \pm 0.9 \%$. Both fine-grained strengthening and the second phase strengthening play essential roles in improving the mechanical properties of the E360 alloy.

\section{Acknowledgements}

This work was supported by the Education Department of Henan Province (20A430010), the National Natural Science Foundation of China (U1804146).

\section{References}

[1] Y. F. Ding, C. Wen, P. Hodgson, Y. Li, Effects of alloying elements on the corrosion behavior and biocompatibility of biodegradable magnesium alloys: A review, J. Mater. Chem. B 2 (2014) 1912-1933. doi:10.1039/c3tb21746a

[2] B. Homayun, A. Afshar, Microstructure, mechanical properties, corrosion behavior and cytotoxicity of $\mathrm{Mg}$ -Zn-Al-Ca alloys as biodegradable materials, J. Alloys Compd. 607 (2014) 1-10. doi:10.1016/j.jallcom.2014.04.059

[3] P. Saha, M. Roy, M. K. Datta, B. Lee, P. N. Kumta, Effects of grain refinement on the biocorrosion and in vitro bioactivity of magnesium, Mater. Sci. Eng. C 57 (2015) 294-303. doi:10.1016/i.msec.2015.07.033

[4] L. Jin, C. X. Chen, G. Z. Jia, Y. T. Li, J. Zhang, H. Huang, B. Kang, G. Y. Yuan, H. Zeng, T. X. Chen, The bioeffects of degradable products derived from a biodegradable $\mathrm{Mg}$-based alloy in macrophages via heterophagy, Acta Biomater. 106 (2020) 428-438. doi:10.1016/j.actbio.2020.02.002

[5] K. Chen, J. W. Dai, X. B. Zhang, Improvement of corrosion resistance of magnesium alloys for biomedical applications, Corros. Rev. 33 (2015) 101-117. doi:10.1515/corrrev-2015-0007

[6] X. B. Zhang, Z. X. Ba, Q. Wang, Uniform corrosion behavior of GZ51K alloy with long period stacking ordered structure for biomedical application, Corros. Sci. 88 (2014) 1-5. doi:10.1016/i.corsci.2014.07.004

[7] J. Geng, J. F. Nie, Microstructure and mechanical properties of extruded Mg-1Ca- $1 \mathrm{Zn}-0.6 \mathrm{Zr}$ alloy, Mater. Sci. Eng. A 653 (2016) 27-34. doi:10.1016/j.msea.2015.12.004
[8] M. Okayasu, S. Takeuchi, M. Matsushita, N. Tada, M. Yamasaki, Y. Kawamura, Mechanical properties and failure characteristics of cast and extruded $\mathrm{Mg}_{97} \mathrm{Y}_{2} \mathrm{Zn}_{1}$ alloys with LPSO phase, Mater. Sci. Eng. A 652 (2016) 14-29. doi:10.1016/j.msea.2015.11.069

[9] M. Kaviani, G. R. Ebrahimi, H. R. Ezatpour, Improving the mechanical properties and biocorrosion resistance of extruded $\mathrm{Mg}-\mathrm{Zn}-\mathrm{Ca}-\mathrm{Mn}$ alloy through hot deformation, Mater. Chem. Phys. 234 (2019) 245-258. doi:10.1016/j.matchemphys.2019.06.010

[10] Y. S. Jeong, W. J. Kim, Enhancement of mechanical properties and corrosion resistance of $\mathrm{Mg}$ -Ca alloys through microstructural refinement by indirect extrusion, Corros. Sci. 82 (2014) 392-403. doi:10.1016/i.corsci.2014.01.041

[11] Y. Z. Du, X. G. Qiao, M. Y. Zheng, K. Wu, S. $\mathrm{W}$. $\mathrm{Xu}$, The microstructure, texture and mechanical properties of extruded Mg-5.3Zn-0.2Ca-0.5Ce (wt.\%) alloy, Mater. Sci. Eng. A 620 (2015) 164-171. doi:10.1016/j.msea.2014.10.028

[12] X. S. Xia, Q. Chen, J. P. Li, D. Y. Shu, C. $\mathrm{Hu}$, S. Huang, Z. Zhao, Characterization of hot deformation behavior of as-extruded Mg-Gd-Y-Zn-Zr alloy, J. Alloys Compd. 610 (2014) 203-211. doi:10.1016/i.jallcom.2014.04.210

[13] Z. Z. Gui, Z. X. Kang, Y. Y. Li, Mechanical and corrosion properties of Mg-Gd-Zn-Zr-Mn biodegradable alloy by hot extrusion, J. Alloys Compd. 685 (2016) 222-230. doi:10.1016/j.jallcom.2016.05.241

[14] C. Xu, M. Y. Zheng, K. Wu, Influence of rolling temperature on the microstructure and mechanical properties of Mg-Gd-Y-Zn-Zr alloy sheets, Mater. Sci. Eng. A 559 (2013) 615-622. doi:10.1016/j.msea.2012.08.151

[15] M. Sabbaghian, R. Mahmudi, K. S. Shi, Microstructure, texture, mechanical properties and biodegradability of extruded Mg- $4 \mathrm{Zn}-x \mathrm{Mn}$ alloys, Mater. Sci. Eng. A 792 (2020) 139828. doi:10.1016/i.msea.2020.139828

[16] H. Yao, J. B. Wen, Y. Xiong, Y. Lu, F. Z. Ren, W. Cao, Extrusion temperature impacts on biometallic Mg-2.0Zn-0.5Zr-3.0Gd (wt.\%) solid-solution alloy, J. Alloys Compd. 739 (2018) 468-480. doi:10.1016/i.jallcom.2017.12.225

[17] J. Zhang, W. Zhang, L. Bian, W. Cheng, X. Niu, C. $\mathrm{Xu}, \mathrm{S}$. Wu, Study of Mg-Gd-Zn-Zr alloys with long period stacking ordered structures, Mater. Sci. Eng. A 585 (2013) 268-276. doi:10.1016/j.msea.2013.07.049

[18] C. Xu, M. Zheng, K. Wu, Effect of final rolling reduction on the microstructure and mechanical properties of Mg-Gd-Y-Zn-Zr alloy sheets, Mater. Sci. Eng. A 559 (2013) 232-240. doi:10.1016/i.msea.2012.08.089

[19] Y. J. Tang, Z. Y. Zhang, L. Jin, J. Dong, Research progress on ageing precipitation of $\mathrm{Mg}$-Gd alloys, Chin. J. Nonferrous Met. 24 (2014) 8-24.

[20] L. L. Wei, L. Chang, Structure of coherent $\mathrm{Mg}_{3} \mathrm{TiO}_{4}$ oxide formed between $\mathrm{TiN}$ and $\mathrm{MgO}$, Mater. Lett. 213 (2018) 227-230. doi:10.1016/j.matlet.2017.11.045

[21] S. B. Li, W. B. Du, X. D. Wang, K. Liu, Z. H. Wang, Effect of $\mathrm{Zr}$ addition on the grain refinement mechanism of Mg-Gd-Er alloys, Acta Metall. Sin. 54 (2018) 911-917. doi:10.11900/0412.1961.2017.00400

[22] C. Cao, Principles of Electrochemistry of Corrosion, 3rd ed., Chemical Industry Press, Beijing, 2008. ISBN: 9787122020451. 
[23] Y. Kang, B. Du, Y. Li, B. Wang, L. Sheng, L. Shao, Y. Zheng, T. Xi, Optimizing mechanical property and cytocompatibility of the biodegradable $\mathrm{Mg}-\mathrm{Zn}-\mathrm{Y}-\mathrm{Nd}$ alloy by hot extrusion and heat treatment, J. Mater. Sci. Technol. 35 (2019) 6-18. doi:10.1016/j.jmst.2018.09.020

[24] F. J. Humphreys, P. N. Kalu, Dislocation-particle interactions during high temperature deformation of two-phase aluminum alloys, Acta Metall. 35 (1987) 2815-2829. doi:10.1016/0001-6160(87)90281-1

[25] H. Y. Yu, H. G. Yan, J. H. Chen, B. Su, Y. Zeng, Y. J. Shen, Z. J. Ma, Effects of minor Gd addition on microstructures and mechanical properties of the high strain-rate rolled $\mathrm{Mg}-\mathrm{Zn}-\mathrm{Zr}$ alloys, J. Alloys Comp. 586 (2014) 757-765. doi:10.1016/j.jallcom.2013.10.005

[26] K. Huang, R. E. Logé, A review of dynamic recrystallization phenomena in metallic materials, Mater. Des. 111 (2016) 548-574. doi:10.1016/j.matdes.2016.09.012

[27] D. X. Zhang, X. Y. Yang, H. Sun, Y. Li, J. Wang, Z. R. Zhang, Y. X. Ye, T. Sakai, Dynamic recrystallization behaviors and the resultant mechanical properties of a Mg-Y-Nd-Zr alloy during hot compression after aging, Mater. Sci. Eng. A 640 (2015) 51-60. doi:10.1016/j.msea.2015.05.076

[28] N. Maazi, N. Rouag, Consideration of Zener drag effect by introducing a limiting radius for neighbourhood in grain growth simulation, J. Cryst. Growth 243 (2002) 361-369. doi:10.1016/S0022-0248(02)01420-3

[29] J. D. Robson, D. T. Henry, B. Davis, Particle effect on recrystallization in magnesium-manganese alloys: Particle-stimulated nucleation, Acta Mater. 57 (2009) 2739-2747. doi:10.1016/i.actamat.2009.02.032

[30] H. Miura, H. Tsukawaki, T, Sakai, J. J. Jonas, Effect of particle/matrix interfacial character on the high-temperature deformation and recrystallization behavior of $\mathrm{Cu}$ with dispersed Fe particles, Acta Mater. 56 (2008) 4944-4952. doi:10.1016/j.actamat.2008.06.012

[31] Y. H. Sun, R. C. Wang, J. Ren, C. Q. Peng, Z. Y. Cai, Microstructure, texture, and mechanical properties of as-extruded $\mathrm{Mg}-x \mathrm{Li}-3 \mathrm{Al}-2 \mathrm{Zn}-0.2 \mathrm{Zr}$ alloys $(x=5,7,8$, 9, 11 wt.\%), Mater. Sci. Eng. A 755 (2019) 201-210. doi:10.1016/j.msea.2019.04.007

[32] S. J. Liu, G. Y. Yang, S. F. Luo, W. Q. Jie, Microstructure and mechanical properties of sand mold cast $\mathrm{Mg}$ $-4.58 \mathrm{Zn}-26 \mathrm{Gd}-0.18 \mathrm{Zr}$ magnesium alloy after different heat treatments, J. Alloys Compd. 644 (2015) 846853. doi:10.1016\%2Fj.jallcom.2015.05.062
[33] H. F. Sun, C. J. Liu, W. B. Fang, Evolution of microstructure and mechanical properties of $\mathrm{Mg}-3.0 \mathrm{Zn}$ $-0.2 \mathrm{Ca}-0.5 \mathrm{Y}$ alloy by extrusion at various temperatures, J. Mater. Process. Technol. 229 (2016) 633-640. doi:10.1016/j.jmatprotec.2015.10.021

[34] A. Srinivasan, Y. Huang, C. L. Mendis, C. Blawert, K. U. Kainer, N. Hort, Investigations on microstructures, mechanical and corrosion properties of Mg-Gd-Zn alloys, Mater. Sci. Eng. A 595 (2014) 224-234. doi:10.1016/j.msea.2013.12.016

[35] F. Y. Cao, Z. M. Shi, G. L. Song, M. Liu, M. S. Dargusch, A. Atrens, Influence of hot rolling on the corrosion behavior of several $\mathrm{Mg}-\mathrm{X}$ alloys, Corros. Sci. 90 (2015) 176-191. doi:10.1016/j.corsci.2014.10.012

[36] A. E. Coy, F. Viejo, P. Skeldon, G. E. Thompson, Susceptibility of rare-earth-magnesium alloys to micro-galvanic corrosion, Corros. Sci. 52 (2010) 3896-3906. doi:10.1016/j.corsci.2010.08.006

[37] W. J. Ding, Y. Z. Xiang, J. W. Chang, Y. H. Peng, Corrosion and electrochemical behaviour of $\mathrm{Mg}-\mathrm{Al}$ alloys and $\mathrm{Mg}-\mathrm{RE}$ alloys in $\mathrm{NaCl}$ solution, Chin. J. Nonferrous. Met. 19 (2009) 1713-1719. doi:1004-0609(2009)19:10<1713:MAXHMR >2.0.TX; $\underline{2-\mathrm{C}}$

[38] S. Gollapudi, Grain size distribution effects on the corrosion behaviour of materials, Corros. Sci. 62 (2012) 90-94. doi:10.1016/i.corsci.2012.04.040

[39] N. N. Aung, W. Zhou, Effect of grain size and twins on corrosion behaviour of AZ31B magnesium alloy, Corros. Sci. 52 (2010) 589-594. doi:10.1016/j.corsci.2009.10.018

[40] Y. F. Luo, Y. L. Deng, L. Q. Guan, L. Y. Ye, X. B. Guo, A. Luo, Effect of grain size and crystal orientation on the corrosion behavior of as-extruded Mg-6Gd-2Y-0.2Zr alloy, Corros. Sci. 164 (2019) 108338. doi:10.1016/j.corsci.2019.108338

[41] G. R. Argade, S. K. Panigrahi, R. S. Mishra, Effects of grain size on the corrosion resistance of wrought magnesium alloys containing neodymium, Corros. Sci. 58 (2012) 145-151. doi:10.1016/j.corsci.2012.01.021

[42] M. Andrei, A. Eliezer, P. L. Bonora, E. M. Gutman, DC and AC polarization study on magnesium alloys influence of the mechanical deformation, Mater. Corros. 53 (2002) 455-461. doi:10.1002/1521-4176(200207)53:7\%3C455::AIDMACO455\%3E3.0.CO;2-4 